Травкина Елена Владимировна

доктор экономических наук, профессор департамента финансовых рынков и банков Финансового университета при Правительстве Российской Федерации

\section{СОВРЕМЕННЫЕ ТЕНДЕНЦИИ И ПЕРСПЕКТИВЫ РАЗВИТИЯ РОССИЙСКОГО РЫНКА ИПОТЕЧНОГО КРЕДИТОВАНИЯ}

\section{Аннотация:}

Одной из самых многогранных и многоаспектных социально значимых категорий в кредитных условиях является ипотечное кредитование. В связи с этим исследование тенденций развития данного сегмента кредитования является важным инструментом в определении направле ний его дальнейшего эффективного развития. В статье проведена оценка основных тенденций в развитии российского ипотечного рынка, среди которых были выделены: активная модернизация законодательной базы, достижение исторического рекорда по объемам выдачи, низкий уровень ипотечных ставок, снижение общего объема концентрации банков с государственным участием в ипотечном сегменте, а также удлинение сроков кредитования. Были выделены факторы, сдерживающие развитие ипотечного кредитования, а также определены направления по снижению их негативного воздействия: внесение дополнений в механизм ипотечных каникул для граждан, доходы которых сократились в связи с инфекционной и кризисной экономической ситуацией; государственное субсидирование ипотечных ставок в качестве меры поддержки уровня выдачи ипотеки и строительного рынка; разработка механизма отсрочки формирования резервов по ссудам заемщиков, чье финансовое положение ухудшилось из-за пандемии.

Ключевые слова:

ипотечное кредитование, российский банковский сектор, эскроу-счет, коммерческие банки, ключевая ставка.
Travkina Elena Vladimirovna

D.Phil. in Economics, Professor, Financial Markets and Banks Department, Financial University under the Government of the Russian Federation

\section{CURRENT TRENDS AND PROSPECTS \\ OF DEVELOPMENT OF THE RUSSIAN MORTGAGE LENDING MARKET}

Summary:

Mortgage lending is one of the most multifaceted and multidimensional socially significant categories in credit conditions. In this regard, the study of trends in the development of this segment of lending is an important tool in determining the direction of its further effective development. The article assesses the main trends in the development of the Russian mortgage market, including: active modernization of the legal framework, achievement of a historical record in terms of issuance, low mortgage rates, reduction in the total concentration of banks with state participation in the mortgage segment as well as extension of loan terms. The factors that hinder the development of mortgage lending were identified, as well as ways to reduce their negative impact: additions to the mechanism of mortgage holidays for citizens whose incomes have decreased due to the infectious and crisis economic situation; state subsidies for mortgage rates as a measure to support the level of mortgage issuance and the construction market; development of a mechanism for delaying the formation of loan reserves for borrowers whose financial situation has deteriorated due to the pandemic.

Keywords:

mortgage lending, Russian banking sector, escrow account, commercial banks, key rate.

Долгосрочное кредитование в целом и ипотечное кредитование в частности играют ключевую роль в получении долгосрочной прибыли коммерческими банками. В экономической литературе активно обсуждаются вопросы банковского ипотечного кредитования и его роли в развитии экономики, что нашло отражение в трудах Е.А. Анненковой, Е.В. Травкиной [1], Ю.В. Морозовой [2], О.С. Рудаковой, С.П. Салтановой [3], Е.П. Терновской [4], К.К. Кумехова, А.Б. Фиапшева [5], Д.А. Шишкиной [6]. Современное развитие российского ипотечного рынка должно учитывать данные по поступательному развитию внутренних и внешних процессов в целях формирования эффективных направлений дальнейшего его функционирования.

Проведем анализ основных тенденций, проявляющихся в сегменте ипотечного кредитования.

1. Модернизация законодательной базы по сегменту ипотечного кредитования. Среди самых значимых моментов модернизации можно выделить:

- вступление с 1 июля 2019 г. в силу новой статьи 6.1-1 Ф3 «О потребительском кредите (займе)» № 353-Ф3 от 21 декабря 2013 г., в соответствии с которой должникам предоставляется право на ипотечные каникулы (льготный период, в течение которого заемщик может уменьшить или приостановить выплаты ипотечного кредита на срок до 6 месяцев). Коммерческие банки обязаны предоставить ипотечные каникулы гражданам в случае тяжелой болезни, оформления инвалидности, потери работы, а также сокращения доходов более чем на 30 \%. Если за полгода 
заемщик так и не сможет найти источник для расчета по ипотечному кредитованию, ему может быть выделен дополнительный срок для решения данного вопроса;

- переход с 1 июля 2019 г. на новую схему финансирования строительства многоквартирных домов через эскроу-счет (условный счет, где учитываются совокупность имущества, документов или денежные средства до наступления определенных обстоятельств или выполнения определенных обязательств). Регламентация правоотношений по договору эскроу-счета установлена § 3 главы 45 и главой 47.1 ГК РФ. Обязательность применения эскроу-счета при долевом строительстве установлена Федеральным законом от 27 июня 2019 г. № 151-Ф3 «О внесении изменений в Федеральный закон «Об участии в долевом строительстве многоквартирных домов и иных объектов недвижимости и о внесении изменений в некоторые законодательные акты Российской Федерации» и отдельные законодательные акты Российской Федерации».

Таким образом, нормативно-правовое регулирование сферы ипотечного кредитования активно трансформируется, способствуя в определенной мере снижению рисков для участников ипотечного рынка.

2. Удешевление стоимости ипотечного кредитования в российской практике. На рисунке 1 показана динамика средневзвешенных процентных ставок по ипотеке с 2012 по 2019 г. [7].

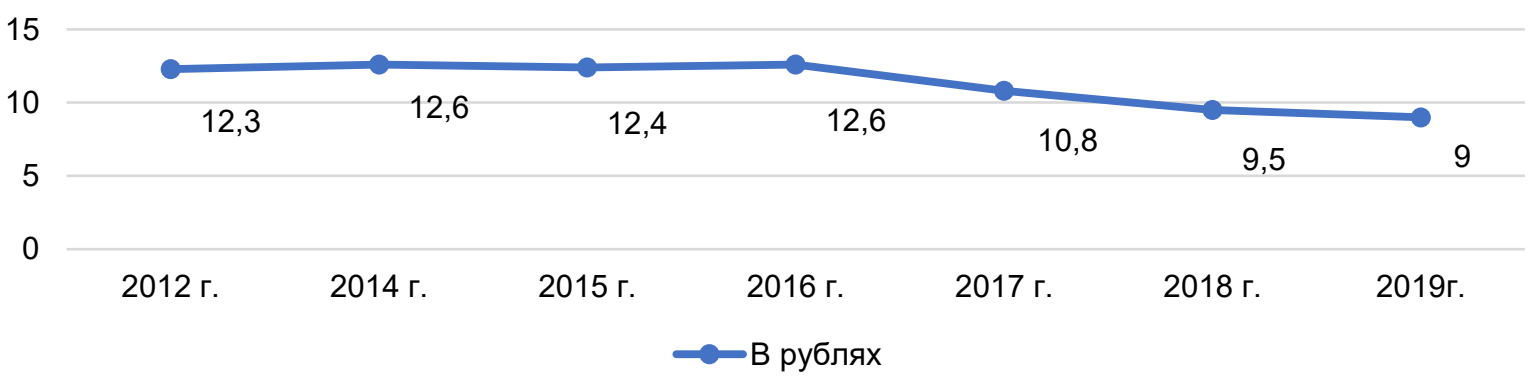

\section{Рисунок 1 - Динамика средневзвешенных процентных ставок по ипотеке в РФ в рублях с 2012 по 2019 г., \%}

По данным Банка России, представленным на рисунке 1, можно говорить о значительном снижении ипотечной средневзвешенной ставки выдачи с 12,6 \% в 2016 г. до 9 \% в 2019 г. В течение 2019 г. ставки выдачи по ипотеке снизились до рекордного уровня за всю историю Российской Федерации, что в свою очередь было обусловлено снижением ключевой ставки (до 6,25 \%). В рамках текущей ситуации при формировании планируемых мероприятий регулятора, направленных на снижение влияния пандемии коронавируса и волатильности на финансовых рынках на финансовый сектор, экономику и граждан, сложно прогнозировать тенденцию динамики изменения ключевой ставки, в том числе и прогнозирование ипотечных ставок в 2020 г.

3. Активный рост сегмента ипотеки. Основным фрактором активизации рынка ипотеки в 2016-2019 гг. является снижение средневзвешенных процентных ставок коммерческих банков на фоне снижения ключевой ставки Банка России (таблица 1) [8].

Таблица 1 - Данные, характеризующие объем ипотечного кредитования в России в 2016-2019 гг.

\begin{tabular}{|l|c|c|c|c|c|c|}
\hline \multicolumn{1}{|c|}{ Наименование } & $\mathbf{2 0 1 6}$ & $\mathbf{2 0 1 7}$ & $\mathbf{2 0 1 8}$ & $\mathbf{2 0 1 9}$ & $\begin{array}{c}\text { Изменение, } \\
\mathbf{2 0 1 9 / 2 0 1 6} \\
\text { (+, -) }\end{array}$ & $\begin{array}{c}\text { Tемп роста, } \\
\mathbf{2 0 1 9 / 2 0 1 6 , \%}\end{array}$ \\
\hline $\begin{array}{l}\text { Количество выданных } \\
\text { ипотечных кредитов, тыс. }\end{array}$ & 856,5 & 1087,0 & 1471,8 & 1300,0 & 443,5 & 152 \\
\hline $\begin{array}{l}\text { Объем выданных ипотеч- } \\
\text { ных кредитов, млрд р. }\end{array}$ & 1473,3 & 2022,9 & 3013,1 & 2847,5 & 1374,2 & 193 \\
\hline $\begin{array}{l}\text { Средневзвешенная ставка } \\
\text { по ипотечным кредитам } \\
\text { в рублях, \% годовых }\end{array}$ & 12,62 & 10,78 & 9,54 & 9,0 & $-3,62$ & 76 \\
\hline $\begin{array}{l}\text { Средний размер кредита } \\
\text { в рублях, млн р. }\end{array}$ & 1,72 & 1,86 & 2,05 & 2,20 & 0,48 & 128 \\
\hline
\end{tabular}

Как видно из представленных данных в таблице 1, за 2016-2019 гг. наблюдалась положительная динамика объема выданных ипотечных жилищных кредитов. При этом наибольшая динамика роста отмечалась именно в 2018 г. в связи с рекордно низкими ставками по ипотечным кредитам. 
Однако в 2019 г. можно наблюдать снижение объемов ипотечного кредитования и снижение количества выданных кредитов. Среди причин данного снижения можно выделить более высокие цены на недвижимость и сокращение объема выдач кредитов с низким первоначальным взносом. Рост цен на недвижимость в условиях стагнации реальных доходов населения привел к увеличению среднего размера ипотечного кредита в анализируемый период.

4. Проявление кредитных рисков. В настоящее время наибольшей проблемой развития ипотечного кредитования в Российской Федерации является крайне низкая платежеспособность населения страны, а также проявляющиеся в связи с этим кредитные риски. Все это негативно отражается на уровне просроченной задолженности в данном сегменте кредитования (таблица 2) [9].

Таблица 2 - Динамика задолженности и просроченной задолженности по ипотечным кредитам за 2016-2019 гг.

\begin{tabular}{|l|c|c|c|c|c|c|}
\hline \multicolumn{1}{|c|}{ Наименование } & $\mathbf{2 0 1 6}$ & $\mathbf{2 0 1 7}$ & $\mathbf{2 0 1 8}$ & $\mathbf{2 0 1 9}$ & $\begin{array}{c}\text { Изменение, } \\
\mathbf{2 0 1 8 / 2 0 1 3} \\
\text { (+, -) }\end{array}$ & $\begin{array}{c}\text { Tемп роста, } \\
\mathbf{2 0 1 9 / 2 0 1 6 ,} \\
\mathbf{\%}\end{array}$ \\
\hline $\begin{array}{l}\text { Задолженность } \\
\text { по кредитам, млрд р. }\end{array}$ & 4464,5 & 5176,0 & 5144,9 & 7470,2 & 3005,7 & 167,3 \\
\hline $\begin{array}{l}\text { В том числе просро- } \\
\text { ченная, млрд р. }\end{array}$ & 52,9 & 53,7 & 54,6 & 63,9 & 11 & 120,8 \\
\hline
\end{tabular}

По данным Банка России, представленным в таблице 2, можно говорить о росте задолженности за 2016-2019 гг. и незначительных изменениях по просроченной задолженности по ипотеке в рублях (уровень весьма низок относительно других видов кредитования населения).

5. Другие тенденции. По данным рейтингового агентства «Эксперт-РА», в 2019 г. наблюдалось снижение общего объема концентрации банков с государственным участием в ипотечном сегменте с 87,5 до 85,1\% (в основном за счет сокращения кредитования Сбербанком России и активизации кредитования частными банками). Кроме того, для ипотечного кредитования в 2019 г. стало характерным удлинение сроков. Заемщики выбирают более длинные сроки кредитования с целью ограничения увеличения долговой нагрузки и фрормирования более комфортного графика погашения (рост среднего срока ипотечного кредита в 2019 г. составил 1,5 года, и в связи с этим он увеличился до 18,2 года) [10].

Подводя итог анализу современного состояния российского ипотечного рынка, следует отметить, что основными сдерживающими факторами развития российского ипотечного рынка в 2020 г., на наш взгляд, будут являться:

1. Недоступность ипотечного кредитования для многих российских заемщиков ввиду высокого существенного первоначального взноса, высоких цен на недвижимость и низкой заработной платы. Одной из значимых причин недоступности ипотечного кредитования для российского населения является низкий уровень заработной платы в сравнении со стоимостью жилья (рисунок 2) [11].

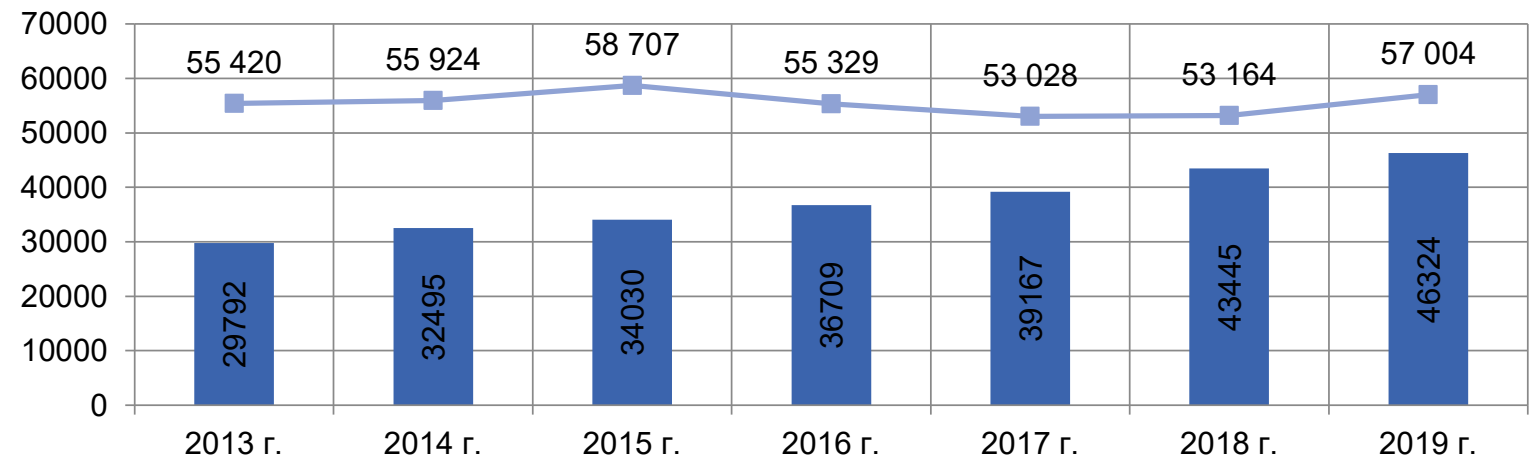

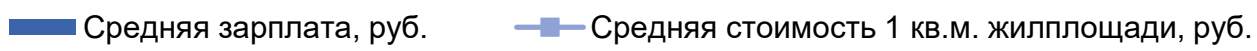

Рисунок 2 - Средний уровень заработной платы населения РФ и средняя стоимость 1 кв. м жилплощади в 2013-2019 гг.

По данным Росстата, представленным на рисунке 2, можно сделать вывод, что средняя зарплата населения в сравнении со стоимостью жилья является невысокой, что является одной из значимых причин недоступности ипотечного кредитования и проявления кредитных рисков в данном сегменте. 
2. Усиление рисков в ипотечном сегменте, обусловленных замедлением экономического роста, инфляционными рисками, а также дальнейшим снижением платежеспособности населения из-за падения цен на нефть и пандемии коронавируса. Сложившаяся ситуация на мировом и российском рынке может в современных условиях изменить денежно-кредитные механизмы, проводимые Банком России. При дальнейшем значительном обесценении рубля и росте инфрляции может произойти увеличение ключевой ставки и соответственно увеличение ипотечных ставок коммерческими банками. Для коммерческих банков сегодня ситуация является достаточно сложной, в связи с чем они приостановили выдачу ипотечных кредитов даже по одобренным заявкам. Данное поведение банков оправдывается проявлением рисков неопределенности в платежеспособности будущих ипотечных заемщиков в связи с экономическим кризисом, проявлением инфрляционных процессов, пандемии, а также сокращением рабочих мест в ряде отраслей, наиболее подверженных влиянию коронавируса.

3. Следующим проблемным фактором на рынке ипотечного кредитования является низкая финансовая грамотность нашего населения. Это обусловливается не совсем рациональным использованием гражданами кредитных средств, а также наличием риска недобросовестности среди кредиторов. Главным условием высокого качества жизни населения является финансово грамотное поведение, которое, к сожалению, в России сейчас находится на достаточно низком уровне.

Для поддержания рынка ипотеки в 2020 г. необходимо осуществить:

1. Разработку мер содействия ипотечным заемщикам. Механизм ипотечных каникул необходимо дополнить возможностями для определенных групп граждан:

1) доходы которых сократились в связи с инфекционной ситуацией;

2) занятых в отраслях, в наибольшей степени пострадавших из-за пандемии (туризм, авиаперевозки, сорера услуг и развлечений);

3) работающих неофициально или получающих «серую» зарплату.

2. Реализацию госпрограммы субсидирования ипотечных ставок для широкого круга заемщиков, которые приобретают квартиры на первичном рынке (примером может послужить госпрограмма субсидирования ставок в 2015-2016 гг.). Государственное субсидирование позволит поддержать уровень выдачи ипотеки, а также строительный рынок, который окажется под давлением из-за возможного увеличения банками ставок кредитования и роста цен на импортные материалы и оборудование в сложившихся кризисных условиях.

3. Для снижения кредитных рисков, с которыми банки столкнутся по всем своим активам (в том числе и по ипотеке) в текущем году, необходимо Банку России разработать механизм отсрочки формирования резервов по ссудам заемщиков, чье финансовое положение ухудшилось из-за пандемии.

Подводя итог проведенному исследованию функционирования ипотечного рынка в современных условиях, стоит отметить, что главной задачей на ближайшую перспективу должно стоять урегулирование сложившейся ситуации в экономике в связи с негативными тенденциями, которые сложились под давлением ситуации на рынке нефтти и пандемии.

\section{Ссылки:}

1. Анненкова Е.А., Травкина Е.В. Электронная закладная в сфере ипотечного кредитования: преимущества и недостатки применения // Финансы и кредит. Т. 25, вып. 5. 2019. Май. С. 1061-1070.

2. Морозова Ю.В. Об оценке предметов залога и их реализации // Наука, образование и инновации : сборник статей Международной научно-практической конференции : в 4 ч. Ч. 2 / отв. ред. А.А. Сукиасян. Уфа, 2016. С. 127-130.

3. Рудакова О.С., Салтанова С.П. Цифровая трансформация банковской деятельности: цель, основные направления, проблемы // Банковское дело. 2019. № 8. С. 45-51.

4. Терновская Е.П. Тенденции и перспективы развития инвестиционного банковского кредитования в российской экономике // Экономика и управление: проблемы, решения. 2017. Т. 6. № 10. С. 48-56.

5. Фиапшев А.Б., Кумехов К.К. Социально ориентированное кредитование: проблемы и направления развития в российской банковской практике // Актуальные проблемы социально-экономического развития России. 2018. № 4. С. 92-101.

6. Шишкина Д.А. Современные тенденции и перспективы развития жилищной ипотеки в России // Вестник Саратовского социально-экономического университета. 2019. № 3 (77). С. 181-184.

7. Центральный банк Российской Федерации [Электронный ресурс] : официальный сайт. URL: http://www.cbr.ru/ (дата обращения: 05.04.2020).

8. Там же.

9. Там же.

10. Эксперт-PA [Электронный ресурс] : официальный сайт. URL: http://www.raexpert.ru (дата обращения: 05.04.2020).

11. Федеральная служба государственной статистики [Электронный ресурc]. URL: https://www.gks.ru/ (дата обращения: 05.04.2020) 